\title{
Physiotherapy student perspectives on synchronous dual- campus learning and teaching
}

\author{
Anestis Divanoglou \\ University of Iceland, Iceland; Central Queensland University, Australia \\ Kenneth Chance-Larsen \\ University of Central Lancashire, United Kingdom \\ Julie Fleming and Michele Wolfe \\ Central Queensland University, Australia
}

\begin{abstract}
An increasing number of universities offer educational programmes across multiple campuses, as a way of facilitating access to tertiary education and filling the shortage of health professionals in rural and regional settings. Offering an equitable learning experience across all sites has been considered an important aspect in any learning and teaching approach. This qualitative study analysed data from 10 focus group discussions and 11 unit evaluations, to explore student perceptions of synchronous dual-campus delivery of a physiotherapy programme in Central Queensland, Australia. An inductive approach to thematic analysis was used. Three themes emerged: (a) Student location influences learning; (b) Videoconferencing impacts learning and teaching; and (c) Dual-campus delivery determines teaching structures and shapes teaching processes. Difficulties related to cross-campus communication, logistics, and opportunities for interaction and engagement were seen as detrimental to synchronous dual-campus delivery. Skill-based demonstrations added another level of complexity. However, students identified a potential benefit from accessing expertise from both campuses. With careful planning and consideration of the potential barriers and facilitators, synchronous dual-campus learning environments can be an effective delivery option for higher education institutions. This study builds on existing literature and suggests a number of strategies that are specific to this mode of programme delivery.
\end{abstract}

\section{Introduction}

In 2013, the Australian Government stated that the geographical distribution of the health workforce did not match the population distribution. The relative number of health professionals was reduced the greater the distance from major centres, with allied health, dental practitioners and medical specialists being in severe shortage in outer regional, remote and very remote areas (Australian Government, 2013).

Offering health-related programmes in regional universities has been suggested as a way to encourage more students from these areas to commence a university education (World Health Organization, 2010). This strategy might address the shortage in the number of health graduates seeking and finding work in regional and remote regions. In a critical review, Wilson et al. (2009) explored interventions aimed at reducing the inequitable distribution of health professionals to rural and remote areas. They reported that geographic origin, especially having attended a rural primary school, was the single factor most strongly associated with rural practice. The model of Rural Clinical Schools (RCS) in Australia, which typically includes 1-2 years of elective placements in rural settings during undergraduate medical studies, has also reported positive outcomes; that is, graduates with RCS experience were 19 times more likely to work in rural areas and $40 \%$ of respondents are still working in rural settings 9 years after graduation (Eley, Synnott, Baker, \& Chater, 2012; Worley et al., 2008). However, a recent Cochrane review (Grobler, Marais, \& Mabunda, 2015) concluded there is a lack of well-designed studies to guide the implementation of interventions to address the shortage of health professionals in underserved areas, namely regional, remote and very remote. 
A lack of firm evidence does not necessarily infer a lack of correlation, and this is perhaps linked to the complexity of undertaking this type of research. Within this uncertain context, an increasing number of universities around the world have explored where and how to locate healthcare programmes. With appropriate government support, universities are now offering programmes across multiple campuses, including some in regional areas (Oz, 2005; Snadden \& Bates, 2005; Taylor, Maharaj, Williams, Chetty, \& Sheldrake, 2010). These offerings can potentially challenge the traditional face-to-face on-campus teaching paradigm, as well as raise issues concerning the quality and equity of the student learning experience. With advances in videoconferencing technology, improved affordability of equipment and fast Internet speeds, students can participate in learning without the need for travel. Universities aspire to provide equality for students, so that studying at a satellite campus is of a comparable standard to that of the main campus (Freeman, 1998; Luck, 2008; Newbury \& McKenzie, 2004).

In their review of Australian higher education institutions, Winchester and Sterk (2006) noted that most higher education institutions offer programmes of study across multiple locations. However, they reported issues around fragmentation, duplication, inconsistency and inequity across a range of learning and teaching activity. While there are some aspects that cannot be easily changed in multi-campus delivery of a university programme (e.g., geographical distance, reliance on technology, location of staff with different expertise and skills on each campus), there are a number of other factors that, if adjusted, could facilitate the perceived equity of the student learning experience. For example, Moore's (1993) theory on transactional distance describes the role of dialogue, structure and learner autonomy on the perceived transactional distance between the learners and the educator. In this model, dialogue and structure are reversely related, with more structure leading to less dialogue and vice versa (Moore, 1993). An effective educational environment has been described as the one that can maximally overcome transactional distance by providing appropriate degrees of dialogue and structure, as well as learner autonomy (Chen \& Willits, 1998; Moore, 1993).

In keeping with rapidly changing requirements and operating contexts, a delivery approach that many higher education institutions have adopted is the flipped curriculum also known as flipped classroom (Scott, 2016). The flipped classroom typically describes a reversal of traditional teaching where students are exposed to learning material outside of class, for example, a video or reading, and then class time is devoted to problemsolving. This concept is closely aligned to the work of Biggs on constructive alignment (Biggs, 2014).

Synchronous multi-campus teaching of a higher education programme offers a number of benefits to educators, students and local communities (Ebden, 2010). Videoconferencing provides access to learners in remote areas and exposes students to a form of communication that they will encounter in their professional lives (Cochrane, 1996). Furthermore, it reduces duplication of teaching (Freeman, 1998), provides equal access to experts and information (Freeman, 1998; Szeto, 2014) and allows more time for educators to conduct research and improve the quality of their teaching.

The teaching of practical skills in a physiotherapy programme is considerable, and such programmes typically dedicate significant time and resources to hands-on practical sessions and case-based tutorials, with a small proportion of contact hours devoted to the more traditional lecture format. In synchronous dual-campus programmes, the learning environment extends to the remote campus through videoconferencing. This approach poses different challenges to the provision of learning via videoconferencing to those of programmes with fewer or no practical curriculum aspects. Although student satisfaction and performance scores can be good indicators of disparities between campuses, several studies report no significant differences between two or three sites regarding average marks, percentage of students who failed the course or performance in externally driven exams (Freeman, 1998; Halabi, 2005; Hortos, Sefcik, Wilson, McDaniel, \& Zemper, 2013; Moridani, 2007; $\mathrm{Oz}, 2005)$. However, even in the absence of these differences, students may still perceive an inequitable learning experience.

The current study explored student perceptions of their learning experiences, as well as factors that influence their sense of equity within the context of a synchronous dual-campus delivery of a physiotherapy programme in Queensland, Australia. Based on these perceptions, the current study discusses educational implications that could potentially improve learning and teaching. 


\section{Learning and teaching context}

The current study was conducted with a newly established Bachelor of Physiotherapy (BPh) programme at a regional university in Australia. The 4-year programme is offered on two regional campuses situated 300 kilometres apart. The university has 16 campuses across Australia, mainly in Queensland. Despite the two campuses included in our study being slightly different in terms of size, we considered them equal in terms that are relevant to the physiotherapy programme. This contrasts with many other studies where there typically is a main and a satellite campus. As a natural consequence of this, when we use the terms on campus and remote campus referring to student quotes, this relates to the student in question and not to the campus location.

A key institutional agenda is strong social inclusion and widening participation, including a range of access pathways into higher education. Nearly half of the physiotherapy students come from a medium socio-economic background, around $40 \%$ from low socio-economic and fewer than $10 \%$ from high socio-economic background.

A consideration within the initial design of the BPh programme was an underpinning educational theory that would align to the learning and teaching environment being developed. Given its status as a dominant educational theory for the past two decades, the lecturers were drawn to constructivism (Jonassen, 1991) as an appropriate pedagogical approach that promotes active student learning. It was important in the design process to capture learners by creating stimulating environments that enabled them to derive meaning for themselves, whilst utilising available technologies.

The BPh curriculum was delivered in real time (synchronously) across the two campuses using a blended approach to teaching, that is, some involving face-to-face and other sessions using videoconferencing. It combined aspects of contemporary learning and teaching pedagogies, such as the flipped classroom (Scott, 2016). Typically, students had access to online resources and were required to complete some activities prior to the class, leaving more time for problem-solving activities and practical skill development in class. Lectures were always delivered synchronously via videoconferencing from one of the two campuses. Tutorial and practical sessions were facilitated either by an on-campus educator, or by the remote-campus educator through videoconferencing. The programme was supported by teaching staff located at either of the campuses, both permanent academics and casual staff, with varying areas of expertise. An educator was always present in each location.

Another important aspect from the institutional perspective is the provision of an equitable learning experience across both campuses. The two regional sites have similar physiotherapy laboratories, facilities and equipment as well as identical high-quality videoconferencing equipment, student microphones, academics and administration support. Technical support was accessible through a priority support telephone line for both sites.

\section{Methods}

This qualitative study employed a combination of focus group discussions (FGDs) and student evaluations that were collected during a 2-year period. This section presents details on the participants, procedures and measures used in the research.

\section{Study participants and data collection}

The first two cohorts of students enrolled in the BPh programme were invited to participate in end-of-year FGDs. Data from these groups were retrieved over a period of 2 years, with students from the first cohort participating twice in FGDs. Overall, there were 10 FGDs that involved 5 to 10 students each. All FGDs were conducted in a university teaching room and lasted approximately 60 minutes each. In addition, we considered qualitative data from 11 student unit evaluations. These are routinely collected for all units via online surveys at mid-term and end of term, and are available to staff in an anonymised format. 
Each FGD was facilitated by two student representatives who were chosen based on their willingness to participate and subsequently received training on how to facilitate an FGD. Further, a focus group guide was developed to assist the students facilitate discussions. The guide listed the areas where we sought student feedback, a list of prompting questions for the facilitators and an open question allowing the opportunity for students to provide feedback on areas they thought were not covered by the moderator. No educators or other university staff were present during the discussions. The student facilitators were asked not to express their personal opinions during the discussions. Instead, they were invited to provide these anonymously in written form after the FGDs.

Each FGD was recorded, and transcribers were instructed to take a denaturalised approach (Oliver, Serovich, \& Mason, 2005). The focus of the analysis was to understand and interpret the data, therefore allowing the exploration of student perspectives and experiences. Transcribers also anonymised transcripts by removing names of students prior to passing the data onto the researchers.

\section{Data analysis}

In order to explore student perspectives, an inductive approach and latent thematic analysis was used, as described by Braun and Clarke (2006). The unit of analysis included the transcriptions of the FGDs, the comments in the online mid-term surveys (MTS) and the end-of-term surveys (ETS) in their entirety. The unit of analysis was inserted into the software programme NVivo version 10. Each data source was first read in its entirety and then analysed by the two principal investigators (AD and KCL) independently. Open coding was used for line-by-line coding of all units of analysis.

Analyst triangulation was conducted in three ways. First, data were analysed by the two researchers (AD and KCL) separately, and emerged codes and categories were discussed. Second, a third researcher (MW) looked at identified codes and categories critically and provided feedback. Third, in order to achieve accuracy, fairness and validity, we sent the manuscript to a purposive sample of the student cohort and asked them to provide comments.

Credibility was maintained by selecting appropriate data collection methods. FGDs provide a collegial environment to express and discuss ideas. Online surveys gave students the opportunity to organise their thoughts in their own time. Both data collection sources were part of the routine programme evaluation and quality improvement, which allowed for a longitudinal (two years) observation of student perceptions. Because of the longitudinal and repetitive nature of data collection, it is very likely that all-important concepts were expressed at some point.

Dependability was improved by providing the same focus group guide to facilitators and the same online survey to participants.

Transferability was facilitated by providing a rich description of the study context and findings, supported by illustrative quotes.

\section{Ethics}

Institutional ethics approval was granted by the university's Human Research Ethics Committee (H15/12-273). All participants provided written informed consent. They were advised that taking part in the FGDs was entirely voluntary, and that their participation would have no consequences on their studies or grades. 


\section{Findings}

Three themes emerged from the data analysis:

1. Student location influences learning.

2. Videoconferencing impacts learning and teaching.

3. Dual-campus delivery determines teaching structures and shapes teaching processes.

This section presents our key findings, which are supported by illustrative quotes. Each quote is identified by the type of data source (i.e., FGD, MTS, ETS). The hierarchy of themes and sub-themes is presented in Table 1. Each sub-theme was characterised as a barrier, a facilitator or both, based on its perceived effect on dualcampus delivery of the curriculum.

Table 1

Hierarchy of themes and sub-themes

\begin{tabular}{|c|c|}
\hline Themes & Sub-themes \\
\hline \multirow{7}{*}{$\begin{array}{l}\text { 1. Student location influences } \\
\text { learning }\end{array}$} & Educator to student ratio (-) \\
\hline & $\begin{array}{l}\text { Access and availability to physical resources differs between campuses } \\
(-)\end{array}$ \\
\hline & $\begin{array}{l}\text { Better engagement with on-campus than remote campus educators and } \\
\text { students (-) }\end{array}$ \\
\hline & Student mobility $(+)$ \\
\hline & Residential school location favours one campus (-) \\
\hline & Competitive comparison between campuses (+/-) \\
\hline & Different learning experience impacts on assessment (-) \\
\hline \multirow{9}{*}{$\begin{array}{l}\text { 2. Videoconferencing impacts } \\
\text { learning and teaching }\end{array}$} & Looking at the screen makes learning and participation difficult (-) \\
\hline & Necessary to have an educator present in all sessions (+/-) \\
\hline & Cannot see demonstrations through the screen (-) \\
\hline & $\begin{array}{l}\text { Videoconferencing allows sharing of educator expertise between } \\
\text { campuses }(+)\end{array}$ \\
\hline & Technical problems during videoconferencing (-) \\
\hline & $\begin{array}{l}\text { Having to use the microphone feels awkward, takes more time and } \\
\text { effort (-) }\end{array}$ \\
\hline & Missing out because of videoconferencing (-) \\
\hline & $\begin{array}{l}\text { Recorded lectures can be valuable when complete and appropriately } \\
\text { edited }(+)\end{array}$ \\
\hline & Balanced use - How much videoconferencing is enough? (+/-) \\
\hline \multirow{7}{*}{$\begin{array}{l}\text { 3. Dual campus delivery } \\
\text { determines teaching structures } \\
\text { and shapes teaching processes }\end{array}$} & Lack of information sharing standards (-) \\
\hline & $\begin{array}{l}\text { Access to information is influenced by the location of unit coordinator } \\
(-)\end{array}$ \\
\hline & Online resources $(+)$ \\
\hline & Expert educator at the remote campus (-) \\
\hline & Different demonstrations from educators $(+/-)$ \\
\hline & Educator mobility $(+)$ \\
\hline & Inconsistent assessment processes (-) \\
\hline
\end{tabular}

Notes. (-) indicates a barrier; (+) indicates a facilitator; (+/-) indicates an aspect that could be either a facilitator or a barrier. 


\section{Theme 1 - Student location influences learning}

This theme emerged from student sentiments around how they saw the quality of their learning experiences being influenced by factors related to their actual location, such as access to educators and facilities. Furthermore, students highlighted that aspects of engagement, with on-site versus remote-campus students and educators, influenced student satisfaction. A shared geographical presence was seen as a fundamental determinant of the student experience.

Varying student-to-educator ratio between campuses created a sense of inequality for the first cohort as one campus had a higher ratio. However, steps were taken to address this issue with the introduction of additional staff from the second year of the programme onwards.

Contrasting access to equipment, facilities and student-directed practice space produced a strong sense of inequity between campuses:

Just not enough facilities for us at the library ... library is way too small for us. Resources are minimal; you have to order stuff from [remote campus] if you want something specific. ... Why isn't it even? If feels like we are a bit left behind. (FGD)

Students felt that they engaged more freely and better with students and educators from the same campus compared with students and educators based on the remote campus:

I find that it is harder to connect with the educator if they are not in front of me, so when the lecture is held at the other campus [remote campus] I feel disconnected to the lecture. (MTS)

I think we have gotten worse with talking on the video, like [remote-campus students] have totally disengaged like no one wants to talk on there, and it makes it a really awkward learning environment. (FGD)

Student mobility across campuses was seen as a way to improve the disconnect between the students and educators across campuses:

Having the two groups meet face-to-face would make it easier for them to communicate in the collaborate sessions rather than being afraid what people are going to think of them. (FGD)

However, when students from one campus were repeatedly required to travel to the other campus, this created some sense of inequity. For example, one of the courses required all students to attend a residential school on one campus to access specialist exercise equipment. This was perceived as unfair by remote-campus students who were required to travel due to the time and cost involved.

Overall, there was a recurring sentiment of competition between the two campuses, where students defined the quality of their learning based on that of the remote campus. Typically, students expressed preference for their own campus, but alongside this there were also reflections that students from the remote campus had reached similar levels of discipline knowledge:

It's hard to see from the other side but I feel that some of the [remote-campus] students aren't as focussed as we are. (FGD)

Students further perceived that cross-campus learning experiences could impact on assessment outcomes. One student said:

I feel that the two classes had been taught very differently off camera, and being marked by someone who had different ideas on clinical practice was challenging. A lot of it had to do with 
[on-campus educator] not being pulled into the loop so she couldn't answer our assessment questions anyway. (MTS)

\section{Theme 2 - Videoconferencing impacts learning and teaching}

The operational and social aspects of dual-campus delivery were central to the students' views. The technical, learning and teaching aspects associated with videoconferencing surfaced as significant issues, especially regarding impact on levels of student engagement. Several students voiced dislike of the videoconferencing system, and felt that it slowed down the learning experience and hampered student engagement, particularly when the educator was based on the remote campus.

Students reported that attending a lecture through a screen had a negative impact on their learning and preferred lectures given on-campus:

The only thing I am not freely happy with is streaming with [remote campus] as I find I tend to lose focus on the lecture because I can't engage as well with the TV as I can with the in-class lecturer. (MTS)

The remoteness of the educator created another dimension that impacted on student engagement, with students noting that communication was impeded due to the difficulty of not seeing verbal cues:

And it's all the non-verbal cues. There's a lot more information attached to a person in the room than a picture. You don't get the same interaction. It makes it harder to concentrate. You really have to focus on staying out of la-la land. (FGD)

The presence of an educator on-campus at all times, even when the session was primarily facilitated by the remote-campus educator, was seen as crucial not only in terms of engagement but also in furthering students' understanding of the material:

Having a lecturer physically present is a requirement if the course is being delivered at the alternate campus. I feel not having someone on-campus to help with questions is a bad idea overall. (MTS)

Students also felt that some demonstrations were difficult to see clearly on a screen, and perceived this as impacting information-sharing between campuses:

Liked the 'drawings' done with the iPad. Trying to demonstrate with models across the [videoconferencing] didn't really seem to work. (MTS)

Despite noting the downsides to videoconferencing, students acknowledged that they benefitted from the expertise of both on-campus and remote-campus educators:

Sharing of lecture responsibility was also a nice element as it got you to think about the material from similar yet different perspectives. (MTS)

Students commented that technical problems encroached on teaching time, which impeded their learning. Technical problems included the time spent to establish a working connection between campuses, along with microphone and sound problems. These issues were particularly frustrating for students who were at the remote campus. One student explained:

When connecting to [remote campus] for lectures, we lose a lot of time and hardly ever completely finish a lecture. [...] If we connected straight away and went straight into the lecture rather than fussing around with sound technology lectures might run on time. (MTS) 
Another factor that was perceived as detrimental to engagement was the use of microphones. There was one wireless microphone designated for student use at each campus, which was switched off most of the time to reduce background noise. Students felt that having to access the microphone was an obstacle to participation and using it felt awkward. Conversely, when students asked questions or contributed comments without using microphones, student at the remote end could not hear what was said, and felt that time was wasted when the educator had to repeat what had been said.

Added to this was the aspect of sound quality, and students found it at times difficult to understand what was being said from the remote end:

[Videoconferenced] lectures are hard to understand sometimes. If they speak too quickly it becomes really muffled. (MTS)

Further to these views, students suggested that careful consideration is given to planning which sessions are videoconferenced and which are delivered off-camera. One student said:

Lectures, sure, that's when we ask questions, even make them longer so we can ask those questions. But at the end of the day, a tutorial, lab class should be that and just prac. You can't see what they are trying to demonstrate on the screen. I may as well just go home and watch YouTube than come here. It needs to get rid of the linking up and just stick to hands on. (FGD)

A positive aspect of videoconferencing between campuses was the availability of recorded lectures. Students suggested that these recordings were a useful learning resource, particularly if they were edited and included the complete lecture.

\section{Theme 3 - Dual-campus delivery determines teaching structures and shapes teaching processes}

Students indicated that the sharing of and access to information relating to teaching content and logistics across the campuses was inconsistent and lacked standardisation. Students perceived this as unfair. They also felt that physical demonstrations during teaching sessions were inconsistent and were impacted by technology. While this variation was regarded by some students to negatively impact their learning experience, others recognised that it had potentially positive impacts through offering a wider perspective.

The standards for sharing information were seen as lacking. This was mainly in the area of educator-to-student information, but also between educator-and-educator. One student commented:

There needs to be clearer communication between [the two campuses], and the information given to both classes at the same time so everyone receives the same information. (ETS)

The location of the students in relation to the unit coordinator seemed to play an important role as students at the remote campus felt that they were missing out, especially in relation to key information relevant to assessment. Timely access to information relevant to each week was seen as important for equity between students from the different campuses. This included both the formal course materials and more ad-hoc information (e.g., clarifications of assessment format). One student said:

Sometimes I feel like this second semester physio course they're [students from remote campus] getting information that we aren't. We didn't seem to know as much as they knew and I don't know why, we were getting a lot of 2nd hand information. A lot of it had to do with [educator on-campus] not being pulled into the loop so she couldn't answer our assessment questions anyway. (FGD) 
Students appreciated the variety of online resources available through the virtual learning environment Moodle:

A lot of the resources were great, textbooks good, Clinics in Motion good. [...] Clinics in Motion is fabulous, it is really helpful, even if it is just a tip for every week. (FGD)

Moodle was seen as a useful tool to share information in a transparent way between campuses, as long as information was timely, did not change constantly and changes were clearly marked:

One of the best aspects [of the Moodle sites] was the inclusion of current/recent announcements on the front page. (FGD)

Students expressed disappointment when they perceived that the remote campus had a more specialist educator:

[The educator had] no real experience in that sort of area. I know that [remote-campus] students were taught by a hydrotherapy instructor. It's not fair for half of the cohort to be instructed from someone who has experience and the others to be going through general things. I felt like it was a complete waste of time. I didn't feel that I took away anything from that lesson. (FGD)

Alongside the concern that the perceived specialist was at the remote campus, it was also recognised that this was an opportunity to develop critical thinking:

[The educator at remote campus] will be showing completely different things to what [the educator on-campus] will be showing us. In a way that's good though because it's teaching us new things and makes you think about it a bit more though. It does have positive and negatives. (FGD)

At the same time, when educators provided demonstrations to on-campus students only, students felt that there may be discrepancies in what they were shown. Educator mobility to allow face-to-face teaching at both campuses was seen as a potentially beneficial aspect of a dual-campus programme. One student suggested that having two educators swap campuses for a couple of weeks would 'provide students with greater opportunity to experience the different skills backgrounds of the lecturers' (FGD).

Varying type, quality and quantity of demonstrations were seen as major factors leading to inequity in practical assessments marks. It was felt that for assessment tasks there were inconsistent expectations and marking standards between examiners across the campuses:

I found there was a double standard between educators [from different campuses] assessing. (MTS)

Students suggested that inconsistencies in teaching and assessment processes between campuses could be avoided through standardisation. They identified the creation of clearer marking standards and expectations, and better-prepared session plans as ways of improving the perceptions of equity of learning, teaching and assessment:

It definitely needs to be standardised, and then the problem also comes up, that we're doing things one way and say [the other educator] is marking it. Is he marking on the way we're taught and presenting, or on the way he's teaching his students? And the same the other way. So I definitely think there needs to be some sort of standard. (FGD)

\section{Discussion}

The findings of this study suggest that most of the challenges in synchronous dual-campus teaching are similar to single campus teaching (Palmgren, Lindquist, Sundberg, Nilsson, \& Laksov, 2014), with the difference that 
they are magnified more so in synchronous dual-campus teaching due to geographical distance. Based on our findings and evidence from the literature, we suggest a number of strategies that could potentially improve the learning experience in synchronous learning and teaching environments, specific to practical skill based programmes such as physiotherapy.

\section{A challenging learning environment}

Students in the current study perceived videoconferencing as a challenging learning environment. Even in the absence of significant differences in examination performance and student satisfaction rates, this study found that there were perceived inequities in learning experiences between campuses. One aspect of this may be related to the difference in transactional distance between the on-campus and remote campus students, and the educator leading the session. Pertinently, this perceived difference in levels of dialogue and structure has been reported to have an impact on student engagement and other aspects of learning and teaching (Chen \& Willits, 1998; Moore, 1993).

A number of factors were seen as contributing to a variability in learning experience, including the studenteducator ratio, quality and quantity of educator demonstrations, inadequate communication between educators, sessions without clear pre-planned outlines, differing level of access to equipment and facilities, and inconsistent expectations and marking from examiners. In addition, there were other factors directly related to videoconferencing, such as reluctance to use the microphone, difficulties seeing demonstrations and a sense of passivity when looking at the screen.

Similar to other forms of synchronous blended education (Park \& Bonk, 2007; Rogers, Graham, Rasmussen, Campbell, \& Ure, 2003; Szeto, 2014), the educator's attention and effort are divided between presenting content in a pedagogically sound manner, engaging with remote-campus students and encouraging cross-campus student interaction. This is a challenging learning environment, and it was perceived as such by students at both campuses. This may slow down the pace of teaching and it may also have implications on interactions between the educator and the students.

In addition to technology preparation, such a complex learning environment necessitates a detailed preparation at an individual (educator) and institution level. These findings add to previous studies (Bower, Dalgarno, Kennedy, Lee, \& Kenney, 2015; Ebden, 2010; Gill, Parker, \& Richardson, 2005; Tennant, 1999) in highlighting that training and professional development for staff inexperienced in the use of videoconferencing technology is crucial to delivering a positive student learning experience.

\section{Practical skill demonstrations}

Several studies have explored videoconferencing of lectures (Freeman, 1998; Steedman, Smith, Martin, \& Keleher, 2006), but only a few with a specific focus on videoconferencing tutorial and practical sessions (Robertson \& Shrewsbury, 2011). Demonstrations of practical skills are key in physiotherapy education. Findings from the current study indicate that when demonstrations were provided through videoconferencing, students from the remote campus had difficulties appreciating all relevant aspects. When demonstrations were not shown through videoconferencing, students from the remote campus felt that they may have missed out on something important which may have an impact on their assessment.

Making sure that there is a good set-up for demonstrations and determining what aspects need to be demonstrated through videoconferencing from each campus are key issues to decreasing perceived inequity between campuses. Furthermore, availability of online resources such as video resources presenting the demonstrated techniques could be used as a point of reference for the students. Additionally, educators could encourage the notion of clinical practice variability as a positive real-life issue. 


\section{Benefiting from available expertise in both campuses}

Students acknowledged that educators in each campus had different expertise, which was seen both as an opportunity and as a challenge. The expertise of the educator at the remote campus, potentially added value and enriched their learning experience. However, videoconferencing alone was considered as an insufficient substitute for lack of expertise on-campus.

The different expertise on each campus created some perceived disparities in teaching and assessment standards. Strategic use of videoconferencing and academics travelling between campuses could be ways to minimise such challenges. Assigning presentations and demonstrations to the most competent educators can potentially improve the perceived benefit of videoconferencing. At the same time, it should be clearly explained to students that there is no evidence suggesting that there are discrepancies in marks and pass rates between campuses in synchronous dual-campus teaching.

\section{Engagement and collaboration}

As suggested by Bower et al. (2015), engagement and collaboration is easier within campus compared to between campuses. The authors found that the sense of community among same campus students and educators was reported to be much stronger compared with across campuses. This also aligns with Moore's (1993) transactional distance theory, where, as the transactional distance decreases, the students feel more connected to the experience, and therefore the learning. In our study, students from the two campuses did not feel as one cohort, but rather as two separate cohorts. In the current study, disengagement of students from the remote campus had an impact on level of engagement of same-campus students. Furthermore, the remote campus was seen as a measuring stick for their own learning experience, which often created a sense of competition.

Students suggested that an educator needed to be present at each campus during videoconferencing. This was previously suggested for lectures (Chakraborty \& Victor, 2004; Hortos et al., 2013; Szeto, 2015) and appeared even more important for tutorial and practical sessions. Chen and Willits (1998) reported that the absence of an on-site educator in a synchronous videoconferencing environment resulted in higher levels of transactional distance. Gill et al. (2005) suggested designating site facilitators for each campus encourages student engagement in the session. While this could be seen as a way to increase structure, as shown previously it works as a means to facilitate dialogue within and between campuses (Chen \& Willits, 1998). Gillies (2008) pointed out that without an educator present at the remote site, the sense of interactivity, the level of motivation and attentiveness may be reduced. This supports our notion that a competent educator should be present in class at all times, even when the session is primarily facilitated by an educator located at the remote campus. In short, it could be suggested therefore, that the level of student engagement in a teaching session is incumbent on the presence of an educator in the room. Last, as suggested by Tennant (1999, p. 89), 'the remote-campus tutor could encourage student engagement and increase interactivity rather than have a "baby sitting role”'.

Bower et al. (2015) suggested that physical meetings and block residential activities can improve cross-campus interaction and engagement. Although this sentiment is supported in our study, it seemed to depend on the timing of such meetings. Furthermore, running individual on-campus sessions with the camera on and the microphone muted could potentially improve the sense of co-presence between the two campuses. Findings from our study also suggested that educators and course coordinators travelling to the remote campus is desirable and improves perceived equity of learning experience. This highlights the need for alternative ways for communication between the course coordinator and remote-campus students, outside the scheduled class time.

\section{Videoconferencing planning}

Taylor et al. (2010) suggested that videoconferencing one component of a study unit (e.g., Jones, Dean, \& HuiChan, 2010; Robertson \& Shrewsbury, 2011), or even a whole study unit (e.g., Freeman, 1998) is completely different to using videoconferencing throughout an on-campus programme. Videoconferencing one study unit may be seen as an interesting innovation of an experimental nature and is often correlated with high levels of 
student satisfaction (Bower et al., 2015). Because the latter involves the whole programme, the perceived value may be lower as potentially it could have irreversible negative implications to student learning and engagement. Overall, our study found that students were concerned about specific aspects of synchronous dual-campus delivery, but not to a degree that would negatively influence their studies as a whole.

Another aspect that may influence student satisfaction is related to student expectations of the unit at the time of their enrolment. Such an explanation may help develop greater acceptance of videoconferencing and therefore meet the expectations of students on how to engage via this medium. It has been suggested that, when videoconferencing is used as a means of synchronous delivery instead of asynchronous delivery, then the former could be perceived as the students' preferred choice (Cunningham, 2014; Smyth, 2005). When it is provided as an alternative to on-campus face-to-face session, it may contribute to a degree of dissatisfaction (Taylor et al., 2010).

Our findings suggest that an eclectic approach to what is delivered through videoconferencing could reduce the negative aspects and improve student satisfaction. Further, if the primary objective of using videoconferencing is to share specialized content across campuses (Gill et al., 2005), then later year units of study may benefit more from videoconferencing as compared to foundational units. Educators would need to determine which sessions or parts of sessions will be videoconferenced, what parts will run completely independently off camera and what parts will run independently with camera on and microphones muted. As Gill et al. (2005, p. 573) suggested, 'when chosen appropriately and delivered effectively, videoconferenced teaching sessions can be stimulating and enjoyable’.

\section{Preparations}

Similar to other findings (Chakraborty \& Victor, 2004; Freeman, 1998; Tennant, 1999), students felt that valuable teaching time was lost because of videoconferencing. As in Freeman's study, neither students nor academics in this study had prior experience of how to best conduct a session under videoconferencing conditions. Videoconferencing is about managing the technology as well as understanding the processes that take place during the connection. As Gill et al. (2005) suggested, staff need training on how to use the technology. Further, they also need more pedagogical help with lecturing skills, and in particular, how to keep students on the remote sites engaged with both peers and educators across both campuses.

Given the current state of technology, some of the challenges related to videoconferencing are noted as inherent to this mode of delivery. Readily accessible microphones are key for student engagement. It is very common that students, especially at the remote campus, are more reluctant to use the microphone and contribute to discussion (Tennant, 1999). Talking fast through the microphone also negatively impacts sound quality. Furthermore, non-verbal communication cues are not visually apparent by remote-campus students. Even the more light-hearted attempts of humour, which are used to encourage student engagement, are not always conveyed in the intended sentiment.

Other suggestions included making resources available to students well in advance, as well as allowing more time when explaining concepts, as a quick pace may disadvantage the remote-campus students (Chakraborty \& Victor, 2004). Offering an integrated flipped classroom model in dual campus delivery was previously reported to enhance the quality of remote-campus students' experiences by facilitating enriched dialogue and learner autonomy (McLaughlin et al., 2013). There is no doubt that videoconferencing can make a complex learning environment. To assist, a well-developed teaching plan that is provided to all educators and staff in advance of each teaching session would be beneficial. Such a teaching plan would also need to accommodate an appropriate degree of dialogue, structure and learner autonomy.

\section{Information sharing}

Information sharing was reported as being an important issue. Students reported that when the unit coordinator was located at the other campus, information was not communicated equally. It was felt that students located at 
the same campus as the unit coordinator received more timely and complete information. As noted by Luck (2003, p. 93), the proximity of the educator increases opportunity for students to seek informal feedback.

Students suggested that important information, for example, about exams, should only be communicated through videoconferencing and/or through the online platform. Moodle was seen as an effective way to share information and to ensure standardisation of provided information. Furthermore, as suggested previously (Luck, 2003), educators will need to explore informal avenues of communication with their students across the two campuses.

\section{Communication between educators}

Students perceived that there was insufficient communication between educators, so that some educators at the remote campus, to that of the unit coordinator, did not know what information and clarifications to provide to students. At times, the on-campus educator refrained from providing clarifications and explanations because they were not sure what specific information they were expected or permitted to disclose. On other occasions, students felt that planning for the session and communication between educators took place during videoconferencing, instead of prior to that. Students felt that valuable teaching time was lost on something that could have been planned prior to the session.

Being clear with what information should be shared through videoconferencing and where to locate information, and having clear teaching plans that are communicated to all educators involved and to students prior to the session are also actions that could contribute to educator-educator and educator-student information sharing. Finally, regular coordination meetings between the educators could improve planning and information sharing, and potentially time management, leading to better student satisfaction.

\section{Study limitations}

All data were routinely retrieved to inform curriculum development, quality assurance and other university processes. The research might have obtained more in-depth data if the purpose of the focus group discussions was entirely devoted to the topic of the current study. However, with routinely collected data, we were able to gather student perceptions over time, at different occasions, and from varying sources. Furthermore, using a variety of information sources allowed triangulation of findings to facilitate identification of key important aspects.

Using external FGD facilitators might have yielded more relevant data. However, using student representatives to facilitate FGDs is likely to have helped participants feel more comfortable and therefore express their opinions more openly. Last, individual follow-up interviews with targeted students may have provided a deeper insight into specific aspects of perceived challenges and suggested strategies.

\section{Research implications}

Future research in this field could consider whether improvements to videoconferencing technology, broadband speed, web-based instructional resources and use of apps such as Doceri and Zoom that promote interaction could contribute towards a more equitable student learning experience. Universities -those already running dual-campus programmes, as well as those planning to do so - could investigate aspects around staff training and how to best facilitate the development of skills required for this form of curriculum delivery, including specific technological competencies but also extension of more traditional learning and teaching methods. Furthermore, future studies could explore different physiotherapy programme types and modes, at pre- and post-registration levels, where students typically have experience from previous tertiary studies including scientific enquiry, and pedagogical methods may be more advanced. 


\section{Conclusion}

To our knowledge, this is the first study exploring student perceptions of synchronous dual-campus delivery of a physiotherapy programme. This mode of learning and teaching brings many and varied challenges, especially because the programme requires the teaching of practical skills. Our data suggest that student location has an impact on learning, as students expressed perceptions of inequity relating to physical resources, and of difficulties developing effective rapport with staff and students from the remote campus. It is also apparent that the use of videoconferencing technology impacts learning and teaching and that the nature of dual-campus delivery can cause communication and logistical difficulties.

However, with careful planning synchronous dual-campus learning environments can be an effective and attractive delivery option in tertiary education institutions. We have made a number of recommendations that are specific to this mode of programme delivery, such as the importance of continuous communication between educators from the two campuses, availability of online resources that demonstrate practical techniques that could be used as a point of reference for both students and educators, the notion of clinical practice variability as a positive real-life issue and strategic use of videoconferencing and academics travelling between campuses. The findings of this study might be relevant to other health programmes with large practical skill components, such as occupational therapy and podiatry.

\section{Acknowledgements}

The authors would like to acknowledge all CQU physiotherapy students from 2013 and 2014 cohorts for participating in the FGDs. We would also like to thank Carmela Birch, Meryck Smith, Alex Piva and Shaun Lynch for reviewing the manuscript and providing feedback. Last, we thank Dr Wendy Madsen for providing expert advice.

\section{Notes}

The principal investigators, Anestis Divanoglou (AD) and Kenneth Chance-Larsen (KCL), are physiotherapy academics involved in designing and delivering the physiotherapy curriculum at CQU, Australia, from its initiation. Co-investigator Julie Fleming (JF) is a curriculum designer with expertise in online education. Coinvestigator Michele Wolfe (MW) is a sociologist with experience in qualitative research.

\section{References}

Australian Government. (2013). Review of Australian Government health workforce programs. Canberra: Author. Retrieved from http://www.health.gov.au/internet/publications/publishing.nsf/Content/workreview-australian-government-health-workforce-programs-toc executive-summary

Biggs, J. (2014). Constructive alignment in university teaching: HERDSA Review of Higher Education, 1, 522). Retrieved from http://herdsa.org.au/system/files/HERDSARHE2014v01p05_0.pdf

Bower, M., Dalgarno, B., Kennedy, G. E., Lee, M. J. W., \& Kenney, J. (2015). Design and implementation factors in blended synchronous learning environments: Outcomes from a cross-case analysis. Computers \& Education, 86, 1-17. doi:10.1016/j.compedu.2015.03.006

Braun, V., \& Clarke, V. (2006). Using thematic analysis in psychology. Qualitative Research in Psychology, 3(2), 77-101. doi:10.1191/1478088706qp063oa

Chakraborty, M., \& Victor, S. (2004). Do’s and don'ts of simultaneous instruction to on-campus and distance students via videoconferencing. Journal of Library Administration, 41(1-2), 97-112. doi:10.1300/J111v41n01_09

Chen, Y.-J., \& Willits, F. K. (1998). A path analysis of the concepts in Moore's theory of transactional distance in a videoconferencing learning environment. The Journal of Distance Education / Revue de l'education Distance, 13(2), 51-65. Retrieved from http://www.ijede.ca/index.php/jde/article/view/141/395 
Cochrane, C. (1996). The use of videoconferencing to support learning: An overview of issues relevant to the library and information profession Education for Information, 14(4), 317-330. doi:10.3233/EFI-199614406

Cunningham, U. (2014). Teaching the disembodied: Othering and activity systems in a blended synchronous learning situation. International Review of Research in Open and Distance Learning, 15(6), 33-51. doi:10.19173/irrodl.v15i6.1793

Ebden, M. (2010, July). We're on a steep learning curve: The benefits and challenges of multi-campus university course delivery. Paper presented at the 33rd HERDSA Annual International Conference, Melbourne, Australia.

Eley, D. S., Synnott, R., Baker, P. G., \& Chater, A. B. (2012). A decade of Australian Rural Clinical School graduates: Where are they and why? Rural and Remote Health, 12, 1937. Retrieved from http://www.rrh.org.au/articles/subviewnew.asp?ArticleID=1937

Freeman, M. (1998). Video conferencing: A solution to the multi-campus large classes problem? British Journal of Educational Technology, 29(3), 197-210. doi:10.1111/1467-8535.00064

Gill, D., Parker, C., \& Richardson, J. (2005). Twelve tips for teaching using videoconferencing. Medical Teacher, 27(7), 573-577. doi:10.1080/01421590500097026

Gillies, D. (2008). Student perspectives on videoconferencing in teacher education at a distance. Distance Education, 29(1), 107-118. doi:10.1080/01587910802004878

Grobler, L., Marais, B. J., \& Mabunda, S. (2015). Interventions for increasing the proportion of health professionals practising in rural and other underserved areas. The Cochrane Database of Systematic Reviews, 6. doi:10.1002/14651858.CD005314.pub3

Halabi, A. K. (2005). Accounting tele teaching lectures: Issues of interaction and performance. Accounting Forum, 29, 207-217. doi:10.1016/j.accfor.2004.10.004

Hortos, K., Sefcik, D., Wilson, S. G., McDaniel, J. T., \& Zemper, E. (2013). Synchronous videoconferencing: Impact on achievement of medical students. Teaching and Learning in Medicine, 25(3), 211-215. doi:10.1080/10401334.2013.797344

Jonassen, D. H. (1991). Objectivism vs. constructivism: Do we need a new philosophical paradigm? Educational Technology: Research and Development, 39(3), 5-14. doi:10.1007/BF02296434

Jones, A. Y. M., Dean, E., \& Hui-Chan, C. (2010). Comparison of teaching and learning outcomes between video-linked, web-based, and classroom tutorials: An innovative international study of profession education in physical therapy. Computers \& Education, 54(4), 1193-1201. doi:10.1016/j.compedu.2009.11.005

Luck, J.-A. (2003). Performing teaching and learning using interactive video-conferencing. [electronic resource]: Flaxton: Post Pressed.

Luck, J. A. T. (2008). Lost in translations: A socio-technical study of interactive videoconferencing at an Australian university (Doctoral dissertation). Central Queensland University, Australia. Retrieved from http://acquire.cqu.edu.au:8080/vital/access/manager/Repository/cqu:4525

McLaughlin, J. E., Griffin, L. M., Esserman, D. A., Davidson, C. A., Glatt, D. M., Roth, M. T., ... Mumper, R. J. (2013). Pharmacy student engagement, performance, and perception in a flipped satellite classroom. American Journal of Pharmaceutical Education, 77(9), 196. doi:10.5688/ajpe779196

Moore, M. G. (1993). Theory of transactional distance. In D. Keegan (Ed.), Theoretical principles of distance education (pp. 22-38). New York, NY: Routledge.

Moridani, M. (2007). Asynchronous video streaming vs. synchronous videoconferencing for teaching a pharmacogenetic pharmacotherapy course. American Journal of Pharmaceutical Education, 71(1), 1-10. doi:10.5688/aj710116

Newbury, J., \& McKenzie, W. (2004). Interactive videoconferencing system for rural health education: A preliminary report. Australian Journal of Rural Health, 12(4), 157-159. doi:10.1111/j.14401854.2004.00589.x

Oliver, D. G., Serovich, J. M., \& Mason, T. L. (2005). Constraints and opportunities with interview transcription: Towards reflection in qualitative research. Social forces: A Scientific Medium of Social Study and Interpretation, 84(2), 1273-1289. doi:10.1353/sof.2006.0023

Oz, H. H. (2005). Synchronous distance interactive classroom conferencing. Teaching and Learning in Medicine, 17(3), 269-273. doi:10.1207/s15328015tlm1703_12 
Palmgren, P. J., Lindquist, I., Sundberg, T., Nilsson, G. H., \& Laksov, K. B. (2014). Exploring perceptions of the educational environment among undergraduate physiotherapy students. International Journal Of Medical Education, 5, 135-146. doi:10.5116/ijme.53a5.7457

Park, Y. J., \& Bonk, C. J. (2007). Is online life a breeze? A case study for promoting synchronous learning in a blended graduate course. MERLOT Journal of Online Learning and Teaching, 3(3), 307-323. Retrieved from http://jolt.merlot.org/vol3no3/park.pdf

Robertson, J. L., \& Shrewsbury, R. P. (2011). Video teleconferencing in the compounding laboratory component of a dual-campus doctor of pharmacy program. American Journal of Pharmaceutical Education, 75(9), 1-6. doi:10.5688/ajpe759181

Rogers, P. C., Graham, C. R., Rasmussen, R., Campbell, J. O., \& Ure, D. M. (2003). CASE 2 Blending faceto-face and distance learners in a synchronous class: Instructor and learner experiences. Quarterly Review of Distance Education, 4(3), 245-251. Retrieved from http://www.infoagepub.com/qrdeissue.html?i=p54c69ed9966e3

Scott, G. (2016). Transforming graduate capabilities \& achievement standards for a sustainable future: Key insights from a 2014-16 Office for Learning \& Teaching National Senior Teaching Fellowship. Retrieved from http://flipcurric.edu.au/sites/flipcurric/media/107.pdf

Smyth, R. (2005). Broadband videoconferencing as a tool for learner-centred distance learning in higher education. British Journal of Educational Technology, 36(5), 805-820. doi:10.1111/j.14678535.2005.00499.X

Snadden, D., \& Bates, J. (2005). Expanding undergraduate medical education in British Columbia: a distributed campus model. Canadian Medical AssociationJjournal = Journal de l'Association Medicale Canadienne, 173(6), 589. doi:10.1503/cmaj.050439

Steedman, M., Smith, K., Martin, F., \& Keleher, P. (2006). Successful cross-campus management of first year engineering courses [electronic resource]. San Diego, CA: IEEE.

Szeto, E. (2014). Bridging the students' and instructor's experiences: Exploring instructional potential of videoconference in multi-campus universities. Turkish Online Journal of Educational Technology, 13(1), 64. Retrieved from http://www.tojet.net/articles/v13i1/1316.pdf

Szeto, E. (2015). Community of inquiry as an instructional approach: What effects of teaching, social and cognitive presences are there in blended synchronous learning and teaching? Computers \& Education, 81, 191-201. doi:10.1016/j.compedu.2014.10.015

Taylor, S. J., Maharaj, P., Williams, K., Chetty, M., \& Sheldrake, C. (2010). Pharmacy students’ perspectives and performance following inter-campus lecture delivery via video-conferencing. Focus on Health Professional Education: A Multi-disciplinary Journal, 12(1), 39-51. Retrieved from https://fohpe.org/FoHPE

Tennant, J. (1999). Teleteaching with large groups: A case study from the Monash experience. Australasian Journal of Educational Technology, 15(1), 80-94. doi:10.14742/ajet.1848

Wilson, N. W., Couper, I. D., De Vries, E., Reid, S., Fish, T., \& Marais, B. J. (2009). A critical review of interventions to redress the inequitable distribution of healthcare professionals to rural and remote areas. Rural Remote Health, 9(2), 1-21. Retrieved from http://www.rrh.org.au/articles/subviewnew.asp?ArticleID=1060

Winchester, H. P. M., \& Sterk, B. F. (2006, July). Multi-campus university management: Lessons from AUQA audit reports. Paper presented at the AUQF 2006 Quality Outcomes and Diversity Forum, Perth, Western Australia.

World Health Organization. (2010). Increasing access to health workers in remote and rural areas through improved retention: Global policy recommendations. Geneva: Author. Retrieved from

http://www.searo.who.int/nepal/mediacentre/2010_increasing_access_to_health_workers_in_remote_and_ rural_areas.pdf

Worley, P., Martin, A., Prideaux, D., Woodman, R., Worley, E., \& Lowe, M. (2008). Vocational career paths of graduate entry medical students at Flinders University: A comparison of rural, remote and tertiary tracks. Medical Journal of Australia, 188(3), 177-178. Retrieved from https://www.mja.com.au/journal/2008/188/3/vocational-career-paths-graduate-entry-medical-studentsflinders-university 
Corresponding author: Anestis Divanoglou, anestis.divanoglou@gmail.com

Australasian Journal of Educational Technology @ 2018.

Please cite as: Divanoglou, A., Chance-Larsen, K., Fleming, J., \& Wolfe, M. (2018). Physiotherapy student perspectives on synchronous dual-campus learning and teaching. Australasian Journal of Educational Technology, 34(3), 88-104. https://doi.org/10.14742/ajet.3460 